\title{
Emergency Department Use and Enrollment in a Medical Home Providing After-Hours Care
}

\author{
Tara Kiran, MD, MSc $c^{1,2,3,4}$ \\ Rabim Moineddin, $\mathrm{PbD}^{2,3}$ \\ Alexander Kopp, $B A^{3}$ \\ Eliot Frymire, $M A^{5,6}$ \\ Richard H. Glazier, MD, \\ $M P H^{1,2,3,7,8}$
}

'Department of Family and Community Medicine and the Centre for Urban Health Solutions in the Li Ka Shing Knowledge Institute, St Michael's Hospital, Toronto, Ontario, Canada

${ }^{2}$ Department of Family and Community Medicine, Faculty of Medicine, University of Toronto, Toronto, Ontario, Canada

${ }^{3}$ Institute for Clinical Evaluative Sciences, Toronto, Ontario, Canada

${ }^{4}$ Health Quality Ontario, Ontario, Canada

${ }^{5}$ Institute for Clinical Evaluative Sciences, Kingston, Ontario, Canada

${ }^{6}$ Centre for Health Services and Policy Research, Queens University, Kingston, Canada

${ }^{7}$ Dalla Lana School of Public Health, University of Toronto, Toronto, Ontario, Canada

${ }^{8}$ Institute of Health Policy, Management and Evaluation, University of Toronto, Toronto, Ontario, Canada

Conflicts of interest: authors report none.

\section{CORRESPONDING AUTHOR}

Tara Kiran, MD, MSc

Health Centre at 80 Bond

80 Bond St

Toronto, Ontario, Canada M5B 1X1

tara.kiran@utoronto.ca

\begin{abstract}
PURPOSE Compared with other high-income countries, Canada and the United States have among the highest rates of emergency department use and the lowest rates of primary care physicians reporting arrangements for after-hours care. We assessed whether enrollment in a medical home mandated to provide afterhours care in Ontario, Canada, was associated with reduced emergency department use.
\end{abstract}

METHODS We conducted a retrospective cohort study using linked administrative data. We included all adult Ontarians enrolled in a medical home between April 1, 2005, and March 31, 2012, who had a minimum of 3 years of outcome data before and after enrollment $(\mathrm{N}=2,945,087)$. We performed a linear segmented analysis with patient-level data to understand the association between initial enrollment in a medical home and emergency department visits, the proportion of all primary care visits occurring on the weekend, and the primary care visit rate. Age, income quintile, comorbidity, and morbidity were included in the modeling as time-varying covariates and sex as a stable variable.

RESULTS The emergency department visit rate increased by $0.8 \%(95 \% \mathrm{Cl}, 0.7 \%$ to $0.9 \%)$ per year before medical home enrollment and by $1.5 \%(95 \% \mathrm{Cl}, 1.4 \%$ to $1.5 \%$ ) per year after the transition. Enrollment in a medical home was associated with an increase in the proportion of visits that occurred on weekends, but a decrease in the overall primary care visit rate.

CONCLUSIONS Enrollment of adult Ontarians in a primary care medical home offering after-hours care was not associated with a reduction in emergency department use. It will therefore be important to prospectively evaluate policy reforms aimed at improving access to primary care outside of conventional hours.

Ann Fam Med 2018;16:419-427. https://doi.org/10.1370/afm.2291.

\section{INTRODUCTION}

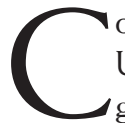

ompared with other high-income countries, Canada and the United States consistently have among the highest rates of emergency department use. ${ }^{1}$ At the same time, both countries provide patients with limited alternatives to access care in the evening or on weekends. Patients seldom report that it is easy to get care after hours without going to the emergency department, while relatively few primary care physicians report having an arrangement for patients to see a physician or nurse after hours. ${ }^{1}$ There is an intuitive connection between greater afterhours access to primary care and lower emergency department use, yet few high-quality studies have evaluated this relationship. ${ }^{2}$ Existing studies are largely cross-sectional, and results have been mixed. ${ }^{2-5}$

The introduction of medical homes in Canada and the United States has been seen as an opportunity to enhance after-hours access in primary care and possibly reduce emergency department use. ${ }^{6,7}$ In Ontario, Canada, more than 10.5 million patients are now cared for in medical homes that include formal patient enrollment, blended physician payment, and physicians working together in groups, in some cases with nonphysician health professionals. ${ }^{8,9}$ One of the main goals of Ontario's medical homes 
was to improve access to primary care. ${ }^{10}$ From the outset, medical homes in the province have been required to provide patients with a minimum number of afterhours evening and weekend sessions per week based on the number of physicians working in the group. We took advantage of this major policy reform to conduct a retrospective cohort analysis to understand whether enrollment in a medical home with mandatory afterhours care was associated with a reduction in emergency department use.

\section{METHODS}

\section{Setting and Context}

Ontario is Canada's largest province, with 14 million residents in 2016. ${ }^{11}$ All permanent residents are insured for medically necessary hospital and physician services through the Ontario Health Insurance Plan (OHIP). Primary care and emergency department visits are free of charge at the point of care.

Primary care physicians in Ontario historically billed the Ministry of Health and Long-Term Care a fee for each service provided, but had no contractual accountability to the government. Since 2002, more than 10.5 million residents and more than 7,000 primary care physicians have transitioned to a medical home (also known as a Patient Enrolment Model).9,10 This transition was voluntary for both physicians and patients; however, most patients chose to maintain their existing relationship with their physician and joined a medical home if their physician chose to do so because few physicians were accepting new patients at the time. ${ }^{12}$ More than $90 \%$ of patients who enrolled in a medical home initially joined a Family Health Group (FHG) where the majority of physician payment is fee for service. The group specifies a minimum of 3 physicians but no maximum size. Other medical home reforms were introduced after the Family Health Group, including a model whereby physicians are paid predominantly by blended capitation (Family Health Organization) and a model incorporating nonphysician health professionals (Family Health Team).

The only major contractual obligation for medical homes was related to after-hours care provision. Physician groups were required to provide one 3-hour afterhours session per week for each physician in the group, initially to a maximum of 5 sessions per week. ${ }^{13}$ Some groups were exempted from the after-hours requirement. Details of the requirements and exemptions are presented in Supplemental Appendix 1, at http://www. annfammed.org/content/16/5/419/suppl/DC1.

Before introduction of medical homes, physicians could bill an "emergency department equivalent" fee code (A888) for patients with unscheduled visits assessed on weekends or statutory holidays. A new fee code (Q012) was introduced in 2004 for medical home physicians to incentivize after-hours care. This fee could be billed together with selected service codes including A888 during scheduled after-hours sessions for patients enrolled in the group and was valued at $30 \%$ of the value of the regular service code. In 2014, the A888 was valued at $\$ 35.40$ and the Q012 payment ranged from $\$ 3.91$ to $\$ 37.50$, with a typical value of $\$ 10.11$.

\section{Study Population and Design}

We conducted a retrospective cohort study to assess the association of initial enrollment in a medical home with emergency department use and other outcomes using data from fiscal years 2002-2003 to 2013-2014. Ontario residents contributed data for a given fiscal year if they were aged 19 years or older, alive, and eligible for Ontario health insurance on March 31 of the fiscal year, had an Ontario postal code; and had at least 1 primary care visit within the previous 2 years. Our primary analysis included the subset of the population who enrolled in a medical home between fiscal years 2005-2006 and 2011-2012 and had a minimum of 3 years of outcome data both before and after enrollment. All analyses were conducted at the patient level.

We excluded rural residents (approximately $8 \%$ of Ontario's population) as access to and organization of health services is markedly different in these areas. In rural areas, emergency departments are often the only available care after hours, and emergency department visit rates are more than double those in urban areas. ${ }^{14}$ In addition, we were able to obtain data on which physicians had an exemption to after-hours provision in 2011 and performed a sensitivity analysis excluding patients who were attached to these physicians in any year during the study period.

Our study used population-based administrative data that were linked using unique, encoded identifiers and analyzed at the Institute for Clinical Evaluative Sciences (ICES). The study was approved by the Research Ethics Board of Sunnybrook Health Sciences Centre in Toronto, Ontario.

\section{Outcome Measures}

Our primary outcome was the emergency department visit rate calculated over a 1 -year period using patientlevel data obtained from the National Ambulatory Care Reporting System. We also evaluated a number of secondary outcomes calculated at the patient level: the proportion of primary care visits that were on the weekend, the overall primary care visit rate, and primary care continuity. We hypothesized that these secondary outcomes would provide context and help 
us interpret our findings related to any change in emergency department visits. We used the A888 billing code to measure the proportion of all primary care visits that occurred on the weekend. We calculated the primary care visit rate over a 2-year period using physician billing data. We used the Usual Provider Continuity Index ${ }^{15}$ to calculate primary care continuity for patients who had 3 or more primary care visits within a 2-year period (Supplemental Appendix 2, at http:// www.annfammed.org/content/16/5/419/suppl/DC1).

\section{Other Data}

We obtained patient age, sex, and postal code from the provincial registry of all patients registered for OHIP. We derived neighborhood income quintile by linking patient postal code to 2006 census data, the most recent census data available. Recent residence was determined via registration with OHIP in the last 10 years. ${ }^{16} \mathrm{We}$ ascertained extent of rural residence using the Rurality Index of Ontario and excluded all patients with a score of 40 or greater. ${ }^{17}$ We used the Johns Hopkins Adjusted Clinical Group software to capture comorbidity using Adjusted Diagnosis Groups (ADGs) (no use, 1-4, 5-9, 10 or more, with the last category indicating high comorbidity) and to assign patients to resource utilization bands (RUBs) based on similar expected health care use $(0$ to 5 , where $0=$ no use, $1=$ low use, $5=$ high use). ${ }^{18}$

\section{Analysis}

We computed descriptive statistics for characteristics for all adult Ontarians for each fiscal year from 2002 2003 to 2013-2014. For each year, we calculated our primary and secondary outcomes for all adult Ontarians as well as the subset included in our regression analyses. For all adult Ontarians, we also assessed trends in emergency department visits stratified by weekend vs weekday and by time of day (9 AM to 5 PM 5 PM to 8 PM, 8 PM to 9 AM). As well, we compared the crude number of emergency department visits, weekday evening billing, and weekend billing for each year of the study period.

We used segmented (piecewise linear) regression modeling to assess the impact of initial enrollment in a medical home on our primary and secondary outcomes. Residents were included in the modeling if they were able to contribute a minimum of 3 years of outcome data before and after enrollment, so we had sufficient data to fit a piecewise linear trend function and assess potential changes in level (intercept) and trend (slope) of the outcomes. The modeling allowed us to account for residents enrolling at any time point between April 1, 2005, and March 31, 2012, and enabled us to use all available data before and after enrollment. Date of enrollment was set as time zero. Patients contributed 3 to 9 years of data before enrollment and 3 to 8 years of data after enrollment (including the year of enrollment).

We included age (in 5-year categories), income quintile, comorbidity (ADGs), and morbidity (RUB) as time-varying covariates in the model as these were calculated every year for every patient and could vary over the time period. Patient sex was included as a stable variable. The variables time, intervention, and time after intervention estimated the secular trend before, the level change immediately after, and the change in trend after initial enrollment in a medical home, respectively. ${ }^{19,20}$ We fit regression models using a Generalized Estimating Equation (GEE) with an AR(1) covariance structure to account for repeated observations within patients. A negative binomial piecewise regression was fit to count data to quantify the level change and change in trend after initial enrollment. For our sensitivity analysis, we repeated the above analyses excluding patients who were attached to physicians with an after-hours exemption. Analyses were performed using SAS Enterprise (SAS Institute Inc).

\section{RESULTS}

Approximately 8.9 million adult patients and 6,813 physicians in Ontario transitioned to a medical home between 2002-2003 and 2013-2014 (Table 1). Patients who transitioned were older, were more likely to be female and long-term residents, and had higher morbidity and comorbidity.

We analyzed secular trends for $11,256,211$ unique individuals (the number of individuals contributing data each year of the study ranged from 7,253,299 in 20022003 to 9,124,254 in 2013-2014). Between 2003 and 2014 , the crude rate of emergency department visits per 1,000 adult Ontarians increased from 363 to 386 (6\%) overall, from 260 to 279 (7\%) on weekdays, and from 103 to 107 (4\%) on weekends (Figure 1A). When considering weekday visits only, the crude visit rate per hour per 1,000 adult Ontarians increased from 15.8 to 17.8 during the day (9 AM to $5 \mathrm{PM}$ ) and from 13.6 to 14.5 in the evening (5 PM to 8 PM), while it remained stable at 7.2 overnight (8 PM to 9 AM) (Figure 1B).

The crude number of weekend physician billings rose from 0.9 million to 1.5 million (Figure 2). In 2014, adult Ontarians made 3.5 million visits to the emergency department and 3.8 million visits to primary care on weeknights or weekends.

We performed regression analyses on 2,945,087 unique individuals (the number of individuals contributing data each year of the study ranged from $2,671,936$ in 2014 to $2,853,236$ in 2008). The emer- 
Table 1. Characteristics of Adult Ontario Residents, Stratified by Medical Home Enrollment

\begin{tabular}{|c|c|c|c|c|}
\hline \multirow[b]{2}{*}{ Characteristic } & \multicolumn{2}{|c|}{2003} & \multicolumn{2}{|c|}{2014} \\
\hline & $\begin{array}{c}\text { Not Enrolled } \\
(n=8,091,210)\end{array}$ & $\begin{array}{c}\text { Enrolled } \\
(\mathrm{n}=310,499)\end{array}$ & $\begin{array}{l}\text { Not Enrolled } \\
(n=555,326)\end{array}$ & $\begin{array}{c}\text { Enrolled } \\
(\mathrm{n}=9,256,897) \\
\end{array}$ \\
\hline \multicolumn{5}{|l|}{ Age-group, No. (\%) } \\
\hline $19-44$ y & $4,187,112(52)$ & $146,983(47)$ & $304,326(55)$ & $4,090,475(44)$ \\
\hline $45-64$ y & $2,581,572(32)$ & $101,953(33)$ & $167,461(30)$ & $3,347,207(36)$ \\
\hline$\geq 65$ y & $1,332,526(16)$ & $61,563(20)$ & $83,539(15)$ & $1,819,215(20)$ \\
\hline Female, No. (\%) & $4,155,330(51)$ & $168,803(54)$ & $226,775(41)$ & $4,853,875(52)$ \\
\hline \multicolumn{5}{|l|}{ Income quintile, No. (\%) } \\
\hline 1 (lowest) & $1,395,871(18)$ & $64,124(21)$ & $141,227(25)$ & $1,670,126(18)$ \\
\hline 2 & $1,600,547(20)$ & $69,220(22)$ & $119,324(21)$ & $1,780,723(19)$ \\
\hline 3 & $1,642,592(20)$ & $63,961(21)$ & $103,928(19)$ & $1,861,775(20)$ \\
\hline 4 & $1,671,211(21)$ & $58,609(19)$ & $98,718(18)$ & $2,007,059(22)$ \\
\hline 5 (highest) & $1,680,989(21)$ & $54,585(18)$ & $92,129(17)$ & $1,937,214(21)$ \\
\hline Recent resident (last 10 years), No. (\%) & $1,126,681(14)$ & $15,989(5)$ & $146,927(26)$ & $896,165(10)$ \\
\hline \multicolumn{5}{|l|}{ Morbidity, RUB, No. (\%) } \\
\hline 0 (none) & $822,226(10)$ & $13,999(5)$ & $180,111(33)$ & $777,702(8)$ \\
\hline 1 & $467,964(6)$ & $19,333(6)$ & $42,302(8)$ & $488,820(5)$ \\
\hline 2 & $1,340,036(17)$ & $57,211(18)$ & $98,759(18)$ & $156,6667(17)$ \\
\hline 3 & $4,049,315(50)$ & $162,702(52)$ & $178,267(32)$ & $4,669,508(50)$ \\
\hline 4 & $1,091,023(13)$ & $43,040(14)$ & $41,793(8)$ & $1,297,450(14)$ \\
\hline 5 (high) & $320,646(4)$ & $14,214(5)$ & $14,094(3)$ & $456,750(5)$ \\
\hline RUB, mean (SD) & $2.6(1.2)$ & $2.8(1.1)$ & $1.8(1.5)$ & $2.7(1.2)$ \\
\hline \multicolumn{5}{|l|}{ Comorbidity, ADGs } \\
\hline No use & $822,390(10)$ & $13,999(5)$ & $180,244(32)$ & $779,679(8)$ \\
\hline 1-4 (low comorbidity) & $3,361,939(42)$ & $148,292(48)$ & $233,860(42)$ & $4,046,915(44)$ \\
\hline $5-9$ & $3,139,319(39)$ & $122,581(39)$ & $116,027(21)$ & $3,549,453(38)$ \\
\hline$\geq 10$ (high comorbidity) & $767,562(9)$ & $25,627(8)$ & $25,195(5)$ & $880,850(10)$ \\
\hline
\end{tabular}

gency department visit rate was slightly higher among individuals included in the regression analyses compared with all Ontario residents, but overall trends were similar (results not shown). Figure 3 illustrates the average crude emergency department visit rate before and after enrollment in a medical home (time of enrollment is 0 ) for those included in the regression analysis.

Regression modeling found that in the years before enrollment in a medical home, the emergency department visit rate rose by $0.8 \%(95 \% \mathrm{CI}, 0.7 \%$ to $0.9 \%)$ per year (Table 2). After enrollment, the emergency department visit rate rose by $1.5 \%(95 \% \mathrm{CI}, 1.4 \%$ to $1.5 \%)$ per year. The difference amounted to an overall increase of $0.7 \%(95 \% \mathrm{CI}, 0.6 \%$ to $0.8 \%)$ per year in the trend. After patient enrollment in a medical home, there was an overall increase in the proportion of weekend visits, a decrease in the primary care visit rate, and a small increase in primary care continuity.

Our sensitivity analysis excluded patients of physicians who received a government exemption for providing after-hours care (approximately 298 medical home physicians caring for 303,593 patients in 2014).
Crude emergency department visit rates were slightly lower for this population, but overall secular trends were similar, as were the regression analysis results evaluating the impact of enrollment on emergency department visit rates (results not shown).

\section{DISCUSSION}

We found that in the Canadian province of Ontario, enrollment in a medical home with mandatory afterhours provision was associated with a small increase in the emergency department visit rate by adults. This change occurred despite an increase in the crude number of primary care weekend billings during the time period and an associated increase in the proportion of all primary care visits that were on the weekend. The volume of after-hours primary care visits was sufficiently high to theoretically affect emergency department visit rates. We found that enrollment in a medical home was also associated with a decrease in the overall primary care visit rate but a small increase in continuity of care. 
Figure 1. Annual number of emergency department visits per 1,000 persons between 2003 and 2014, unadjusted for patient characteristics.

A. Emergency department visit rate stratified by weekday and weekend.

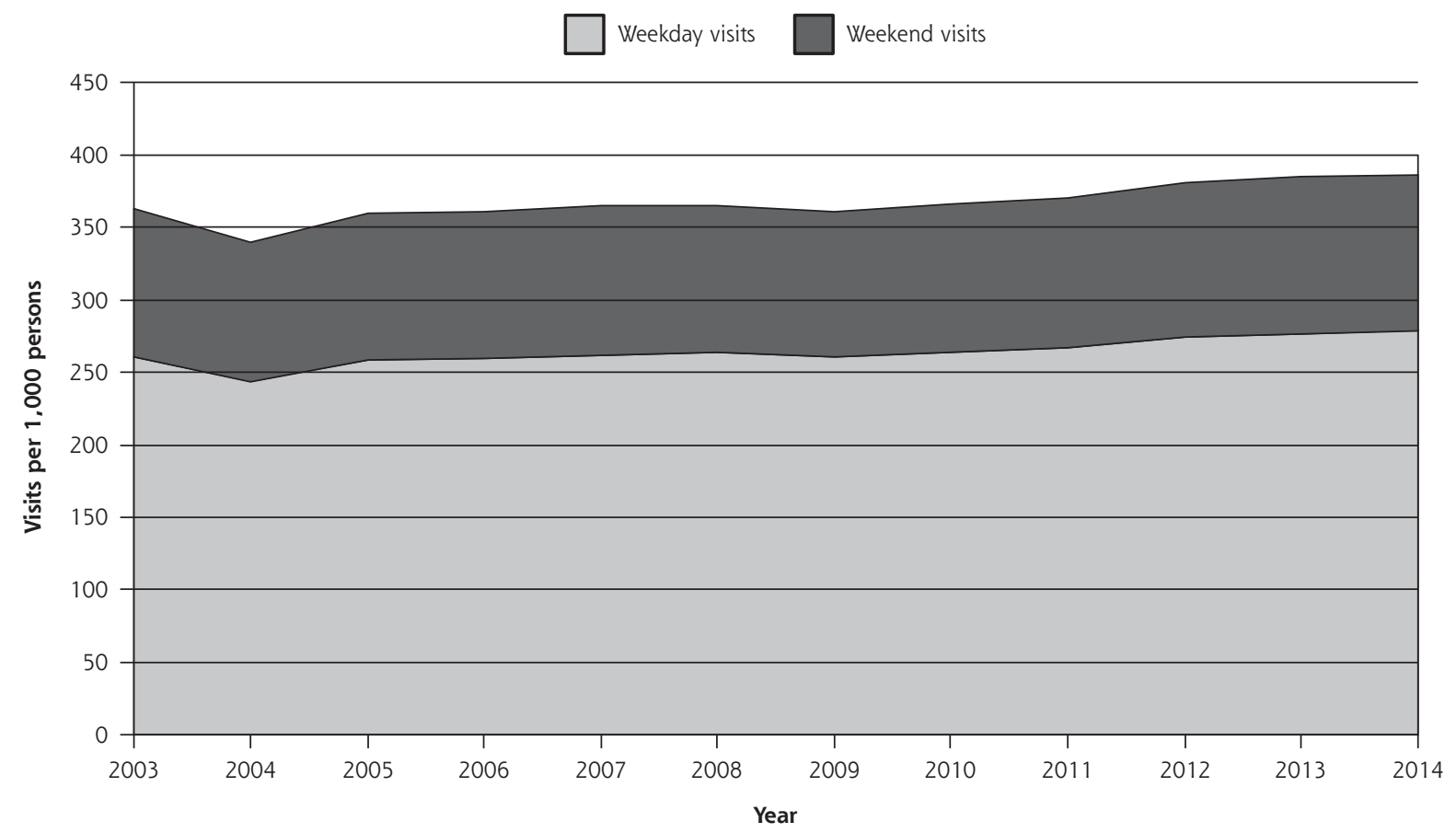

B. Emergency department visit rate per hour on weekdays stratified by time of day.

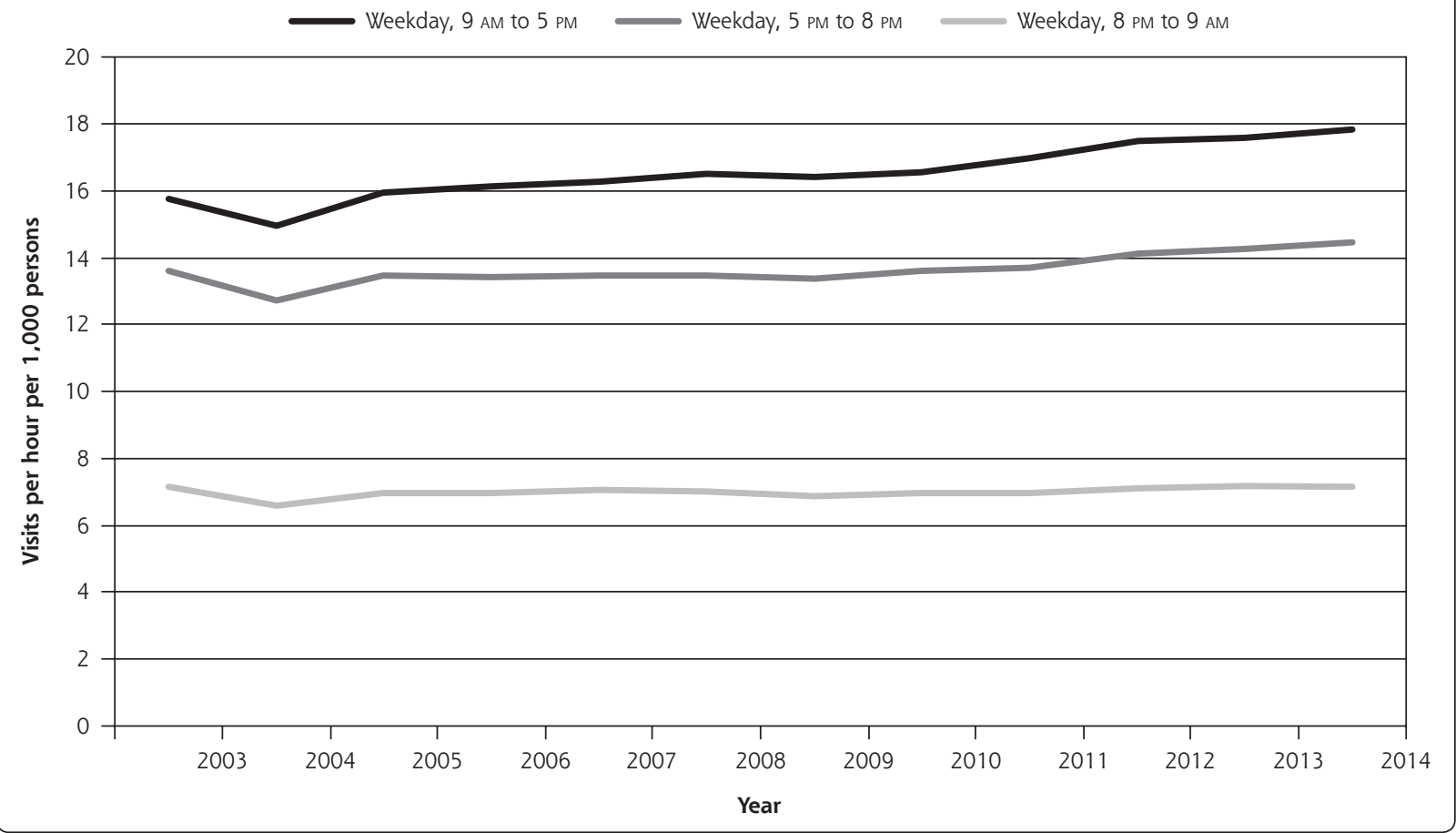

The decline in the primary care visit rate associated with medical home enrollment may be one explanation for the increase in emergency department visits. Reforms were implemented in the context of a relatively fixed primary care workforce, and increased after-hours primary care may have been offset by a 
Figure 2. Crude number of emergency department visits and after-hours primary care visits for adult Ontarians between 2003 and 2014.

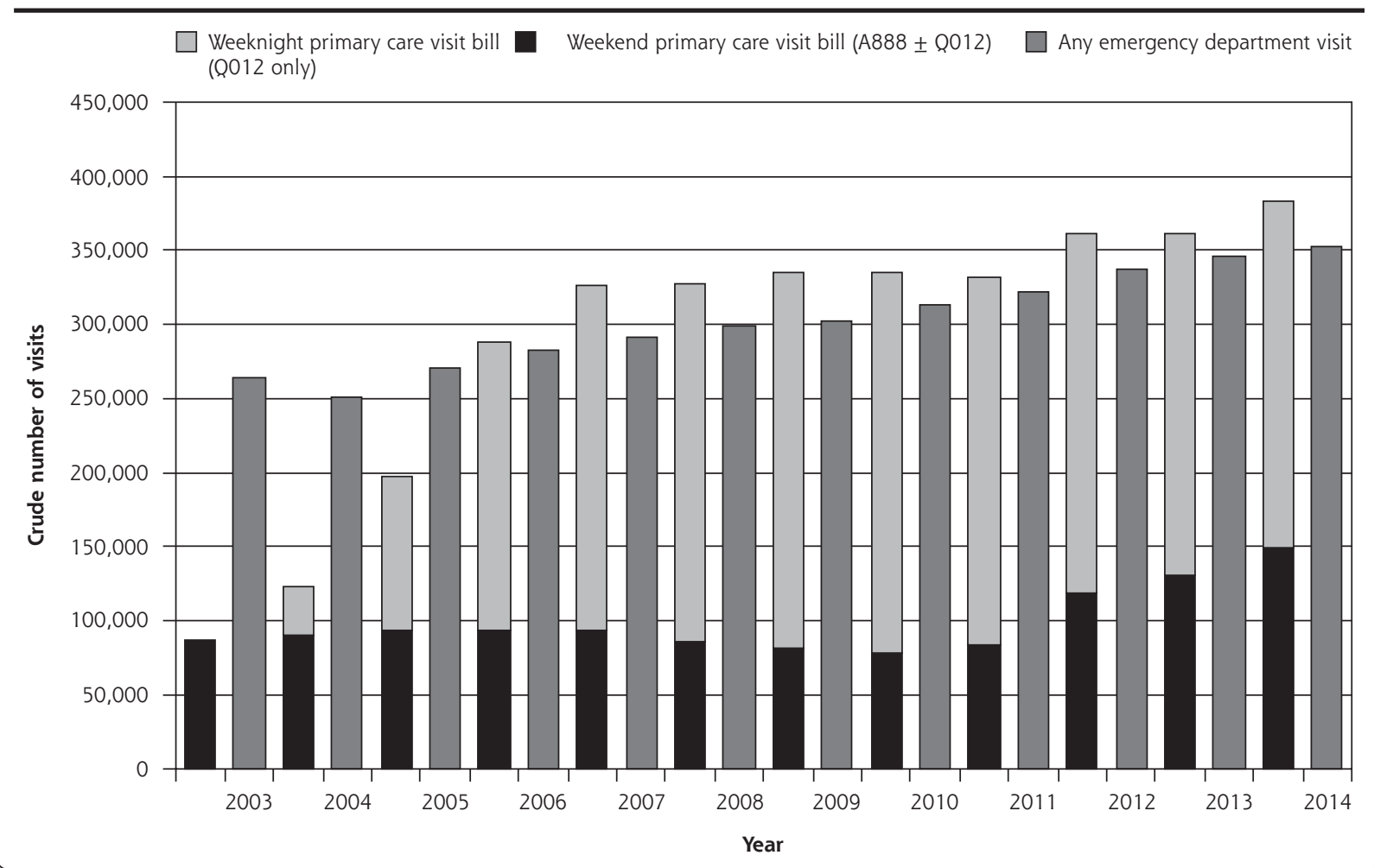

Figure 3. Crude emergency department visit rate per 1,000 persons before vs after enrollment in a medical home for the subset of patients included in regression analysis.

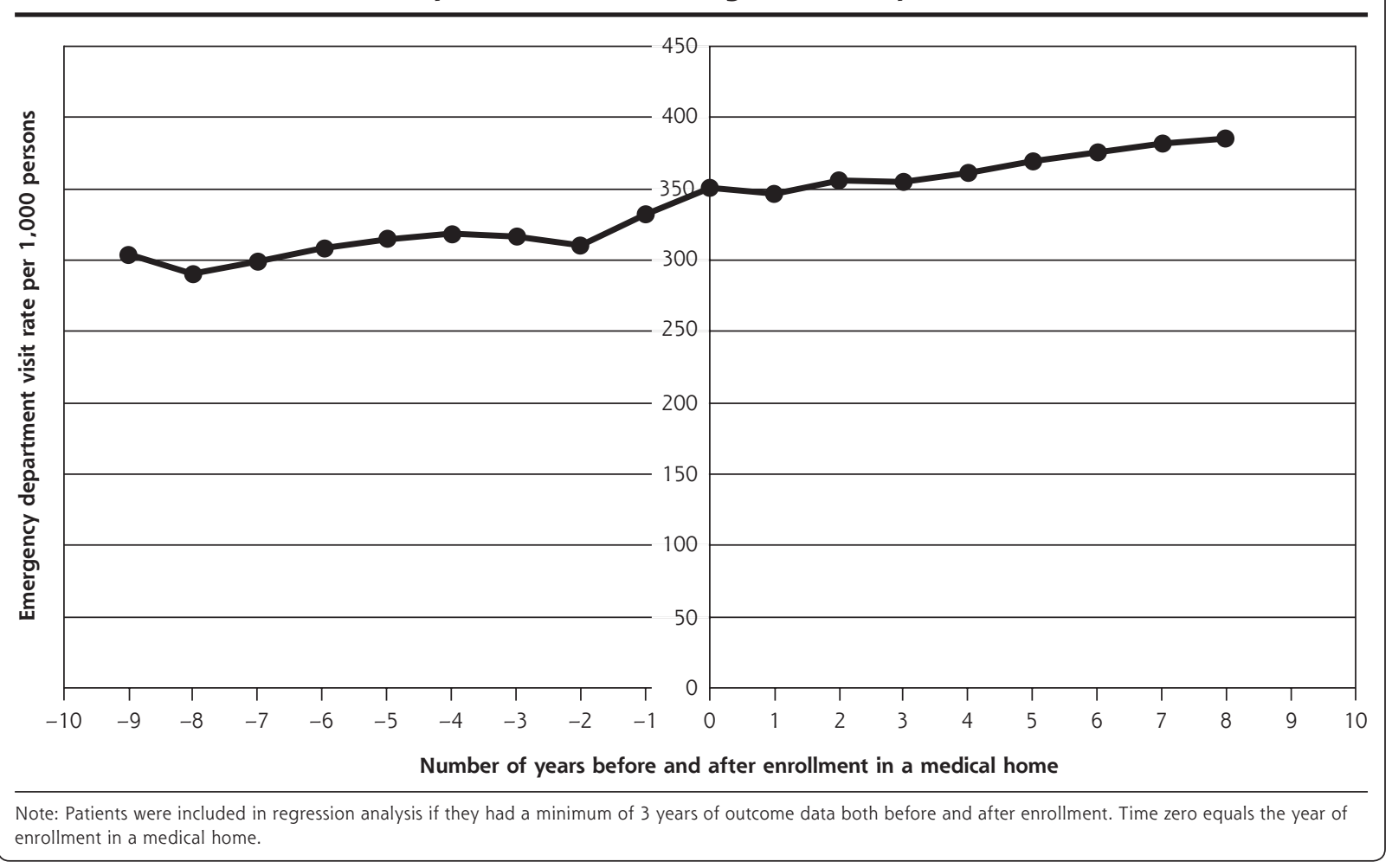


Table 2. Trends in Health Outcomes of Adult Ontarians Before and After Enrollment in a Medical Home

\begin{tabular}{|c|c|c|c|}
\hline \multirow[b]{2}{*}{ Outcome } & \multicolumn{3}{|c|}{ Trend, \% Change per Year $(95 \% \mathrm{Cl})$} \\
\hline & Before Enrollment & After Enrollment ${ }^{a}$ & Difference \\
\hline $\begin{array}{l}\text { Emergency department } \\
\text { visit rate }\end{array}$ & $0.8(0.7$ to 0.9$)$ & $1.5(1.4$ to 1.5$)$ & $0.7(0.6$ to 0.8$)$ \\
\hline Primary care continuity & $-0.8(-0.9$ to -0.8$)$ & $0.4(0.3$ to 0.4$)$ & $1.2(1.2$ to 1.2$)$ \\
\hline Primary care visit rate & 0.6 (0.6 to 0.7$)$ & $-2.2(-2.1$ to -2.3$)$ & $-2.8(-2.8$ to -2.8$)$ \\
\hline $\begin{array}{l}\text { Proportion of primary care } \\
\text { visits with A888 code }\end{array}$ & $4.8(4.6$ to 5.0$)$ & $8.5(8.4$ to 8.6$)$ & $3.5(3.4$ to 3.7$)$ \\
\hline \multicolumn{4}{|c|}{$\begin{array}{l}\text { Notes: Regression model included age (in 5-year categories), income quintile, comorbidity (adjusted diagnostic } \\
\text { groups), and morbidity (resource utilization band) as time-varying covariates and sex as a stable variable. Fiscal } \\
\text { year was included to account for secular trends. Table presents the percent change per year in the outcome based } \\
\text { on the rate ratio after results of the original model performed on log(e) scale were taken to the exponent. Rate } \\
\text { ratios were calculated using negative binomial regression analysis. Full model parameters on the log(e) scale are } \\
\text { available in Supplemental Appendix } 3 \text { (http://www.annfammed.org/content/16/5/419/suppl/DC1). }\end{array}$} \\
\hline \multicolumn{4}{|c|}{$\begin{array}{l}\text { a Calculated by adding the baseline trend and the change in trend in the original parameter estimates generated } \\
\text { using log(e) scale. Estimates presented in this table are converted, so will not add up in the same way. }\end{array}$} \\
\hline
\end{tabular}

requirements and recommended that the government impose a penalty for not meeting contractual requirements. ${ }^{25}$

Another explanation for the increase in the emergency department visit rate is that the introduction of mandatory after-hours provision with medical homes simply fueled greater demand for health care. Supply-induced demand can occur because of easier access to primary care but also because access to primary care may stimulate demand for other health care services. ${ }^{26}$ In the United Kingdom, improved

decrease in regular office hours. This hypothesis is supported by our finding that the secular increase in the emergency department visit rate seemed to be driven largely by an increase in visits between 9 AM and 5 PM on weekdays. By 2011, 45\% of patients in new medical home models were cared for by physicians who received about $70 \%$ of their income from blended capitation. ${ }^{9}$ These physicians incur a financial penalty when their patients make a visit to a primary care physician outside their group (eg, at a walk-in clinic) but receive no penalty if a patient visits the emergency department. ${ }^{8}$ As well, these physicians have an inherent financial incentive to enroll new patients but no accountability for providing timely access during regular office hours. Other studies have found that timely access to primary care is associated with lower emergency department use $e^{5,21,22}$ and that patients who report difficulty booking an appointment during regular hours are more likely to access care out of hours. ${ }^{23}$

In our study, there was considerable physician billing for after-hours care, which suggests medical home physicians, on average, increased after-hours service provision for patients. It is unclear, however, to what extent groups met contractual obligations and patient demand. Specifically, we have no information on how evening and weekend hours were advertised to patients, how after-hours clinics were staffed, and, crucially, whether the clinics were offered in addition to or as a substitute for regular daytime hours. Previous research has found that $60 \%$ of after-hours telephone messages from the offices of medical home physicians direct patients to seek care from the emergency department, while only $32 \%$ inform patients of their own after-hours clinic. ${ }^{24}$ In her 2016 report, Ontario's Auditor General found a sizable percentage of medical homes were not meeting after-hours access to care for relatively minor conditions through the expansion of walk-in centers and minor injury units was met with an increase in demand for these services, but no corresponding decrease in emergency department use. ${ }^{27}$ Most other studies evaluating the relationship between after-hours primary care and emergency department use have been cross-sectional, and results have been mixed. Some have shown an association between patient-reported access to after-hours care and emergency department use, ${ }^{4,28}$ whereas others have found no association. ${ }^{2,3,5}$ A pilot study in Manchester, England, of enhanced 7-day access to primary care for both routine and urgent concerns found a $26 \%$ relative reduction in patient-initiated emergency department visits for minor conditions, but a nonsignificant 3\% relative reduction in total emergency department visits. ${ }^{29}$ That study analyzed outcomes for approximately 350,000 patients 1 year after enhanced access was introduced, whereas our study assessed outcomes for 4.4 million adults 3 to 8 years after they joined a medical home with mandated after-hours care.

Mandating after-hours care was just one component of Ontario's primary care reforms. Evaluation of other aspects have been mixed, finding minimal to no effect of financial incentives on preventive care ${ }^{9,30-32}$ but some positive effect from multidisciplinary teams. ${ }^{9}$ Future research should evaluate the impact of teambased care and payment reforms on emergency department use-in Ontario and elsewhere.

Our study has notable limitations. First, we did not have a control group, and the direction of potential bias is unknown. The small number of patients who remained with fee-for-service physicians were likely unattached and receiving care from walk-in clinics, so they would not have been an appropriate control group. ${ }^{33}$ We did not have access to data in other prov- 
inces, but even if we had, the comparison would have been muddied by differences in context, including distinct but parallel reforms. Instead, we conducted a quasi-experimental study wherein each patient acted as his or her own control. Second, we were limited by the administrative data available. For example, we were unable to capture care provided by telephone or e-mail, or to determine whether patients saw a nonphysician team member, as neither aspect is captured by physician billing. These data would have helped us interpret the changes we found in primary care visit rate. Third, our primary analysis included patients who had at least 6 years of outcome data, thereby excluding any who died during the time period, however, that subset is a relatively small group, so unlikely to have substantially affected our results. Fourth, our study evaluated the policy introducing medical homes with mandated after-hours care, but we were unable to assess specifics of how after-hours care was implemented, which may have provided us with further insights into our findings. Finally, we were unable to isolate the effect of mandating after-hours provision from other aspects of enrollment in a medical home, such as formal patient enrollment and financial incentives for chronic disease. Reforms were designed to improve access to care, however, and teasing out the effects of the components is less relevant given our negative findings.

In conclusion, we found that enrollment in a medical home with mandated after-hours care was not associated with a reduction in emergency department use. Governments in Canada and the United Kingdom have recently pledged improved access to primary care after hours, ${ }^{34,35}$ and our study highlights the importance of prospectively evaluating such reforms. Improving after-hours access to primary care may hold value for patients ${ }_{i}$ however, benefits must be weighed against potential opportunity costs, including an increase in physician workload ${ }^{36}$ a decrease in daytime access for patients given a fixed primary care workforce already stretched by existing demand, or both.

To read or post commentaries in response to this article, see it online at http://www.AnnFamMed.org/content/16/5/419.

Key words: medical home; after-hours care; emergency care; access to health care; health care utilization; continuity of patient care; health care reform; primary care

Submitted November 21, 2017; submitted, revised, May 7, 2018; accepted June 7, 2018.

Previous presentations: Kiran T. Did introduction of medical homes with mandatory after-hours provision reduce emergency department use? Clinical and Population Health Rounds, St Michael's Hospital, Toronto, Ontario. Oral presentation. January 19, 2017.

Kiran T, Moineddin R, Kopp A, Frymire E, Glazier R. Did introduction of medical homes with mandatory after-hours provision reduce emer- gency department use? Primary Health Care Research Rounds, Ministry of Health and Long-Term Care, Toronto, Ontario. Oral presentation. December 13, 2016.

Kiran T, Moineddin R, Kopp A, Frymire E, Glazier R. Did introduction of medical homes with mandatory after-hours provision reduce emergency department use? Canadian Association of Health Services and Policy Research Conference, Toronto, Ontario. Oral presentation. May 24, 2017.

Kiran T, Moineddin R, Kopp A, Frymire E, Glazier R. Did introduction of medical homes with mandatory after-hours provision reduce emergency department use? North American Primary Care Research Group Annual Meeting; Nov 12-16, 2016; Colorado Springs, Colorado. Oral presentation.

Funding support: This study was supported by an Applied Health Research Question Grant from the INSPIRE Primary Health Care Research Program, which was funded through the Health Systems Research Program of the Ontario Ministry of Health and Long Term Care (PI: Tara Kiran). This study was supported by the Institute for Clinical Evaluative Sciences, which is funded by annual grants from the Ontario Ministry of Health and Long-Term Care. Drs Kiran and Glazier are supported as Clinician Scientists by the Department of Family and Community Medicine at the University of Toronto and at St Michael's Hospital. Dr Kiran is the Fidani Chair in Improvement and Innovation at the University of Toronto. She is also supported by the Canadian Institutes of Health Research and Health Quality Ontario as an Embedded Clinician Researcher.

Disclaimer: The opinions, results, and conclusions reported in this article are those of the authors and are independent from the funding sources. No endorsement by the Institute for Clinical Evaluative Sciences or the Ontario Ministry of Health and Long-Term Care is intended or should be inferred. Parts of this material are based on data and information compiled and provided by Canadian Institute for Health Information (ClHI); however, the analyses, conclusions, opinions, and statements expressed herein are those of the authors and not necessarily those of $\mathrm{ClHI}$.

Acknowledgment: The authors would like to thank Dr Michael Schull, Dr Garry Salisbury, and Dr Irfan Dhalla for their comments on the manuscript.

- Supplementary materials: Available at http://www.AnnFamMed. org/content/16/5/419/suppl/DC1/.

\section{References}

1. Robin O, Schoen C. Chartpack: The Commonwealth Fund 2013 International Health Policy Survey in Eleven Countries. Washington, DC: Commonwealth Fund; 2013.

2. Ismail SA, Gibbons DC, Gnani S. Reducing inappropriate accident and emergency department attendances: a systematic review of primary care service interventions. Br J Gen Pract. 2013;63(617): e813-e820.

3. Harris MJ, Patel B, Bowen S. Primary care access and its relationship with emergency department utilisation: an observational, cross-sectional, ecological study. Br J Gen Pract. 2011;61(593): e787-e793.

4. O'Malley AS. After-hours access to primary care practices linked with lower emergency department use and less unmet medical need. Health Aff (Millwood). 2013;32(1):175-183.

5. van den Berg MJ, van Loenen T, Westert GP. Accessible and continuous primary care may help reduce rates of emergency department use. An international survey in 34 countries. Fam Pract. 2016;33(1): 42-50.

6. Margolius $D$, Bodenheimer T. Redesigning after-hours primary care. Ann Intern Med. 2011;155(2):131-132. 
7. Reid RJ, Fishman PA, Yu O, et al. Patient-centered medical home demonstration: a prospective, quasi-experimental, before and after evaluation. Am J Manag Care. 2009;15(9):e71-e87.

8. Glazier RH, Redelmeier DA. Building the patient-centered medical home in Ontario. JAMA. 2010;303(21):2186-2187.

9. Kiran T, Kopp A, Moineddin R, Glazier RH. Longitudinal evaluation of physician payment reform and team-based care for chronic disease management and prevention. CMAJ. 2015;187(17):E494-E502.

10. Hutchison B, Glazier R. Ontario's primary care reforms have transformed the local care landscape, but a plan is needed for ongoing improvement. Health Aff (Millwood). 2013;32(4):695-703.

11. Statistics Canada. Population by year, by province and territory. 2016. http://www.statcan.gc.ca/tables-tableaux/sum-som/l01/cst01/ demo02a-eng.htm. Accessed Nov 24, 2016

12. Canadian Institute for Health Information. What Do We Know About Family Physicians Who Accept New Patients? https://secure. cihi.ca/free products/aib what do we know_en.pdf. Published Jul 2010. Accessed Nov 24, 2016.

13. Ministry of Health and Long-Term Care. After hours service requirements update. http://www.health.gov.on.ca/en/pro/programs/ohip/ bulletins/11000/bul11007_2.pdf. Published Jan 2011. Accessed Nov 24, 2016

14. Glazier RHZB, Rayner J. Comparison of Primary Care Models in Ontario by Demographics, Case Mix and Emergency Department Use, 2008/09 to 2009/10. ICES Investigative Report. Toronto, Ontario, Canada: Institute for Clinical Evaluative Sciences; 2012.

15. Breslau N, Reeb KG. Continuity of care in a university-based prac tice. J Med Educ. 1975;50(10):965-969.

16. Ray JG, Vermeulen MJ, Schull MJ, Singh G, Shah R, Redelmeier DA Results of the recent immigrant pregnancy and perinatal long-term evaluation study (RIPPLES). CMAJ. 2007;176(10):1419-1426.

17. Kralj B. Measuring "Rurality" for Purposes of Health-Care Planning: an Empirical Measure for Ontario. Toronto, Ontario, Canada: Ontario Medical Association; 2005.

18. The Johns Hopkins University. The Johns Hopkins ACG system. http:// www.acg.jhsph.org/. Published 2012. Accessed Mar 27, 2012.

19. Naumova EN, Must A, Laird NM. Tutorial in Biostatistics: evaluating the impact of 'critical periods' in longitudinal studies of growth using piecewise mixed effects models. Int J Epidemiol. 2001;30(6): 1332-1341.

20. Wagner AK, Soumerai SB, Zhang F, Ross-Degnan D. Segmented regression analysis of interrupted time series studies in medication use research. J Clin Pharm Ther. 2002;27(4):299-309.

21. Cowling TE, Cecil EV, Soljak MA, et al. Access to primary care and visits to emergency departments in England: a cross-sectional, population-based study. PLoS One. 2013;8(6):e66699.
22. Mian O, Pong R. Does better access to FPs decrease the likelihood of emergency department use? Results from the Primary Care Access Survey. Can Fam Physician. 2012;58(11):e658-e666.

23. Zhou Y, Abel G, Warren F, Roland M, Campbell J, Lyratzopoulos G. Do difficulties in accessing in-hours primary care predict higher use of out-of-hours GP services? Evidence from an English National Patient Survey. Emerg Med. 2015;32(5):373-378.

24. Howard M, Randall GE. After-hours information given by telephone by family physicians in Ontario. Healthc Policy. 2009;5(2):106-115.

25. Office of the Auditor General of Ontario. Section 3.11: Physician Billing. 2016 Annual Report: Toronto, Ontario, Canada: Queen's Printer for Ontario; 2016

26. Rosen R. Meeting Need or Fuelling Demand? Improved Access to Primary Care and Supply-Induced Demand. London, UK: Nuffield Trust; 2014

27. Appleby J. John Appleby: pressures on accident and emergency services. The Kings Fund. https://www.kingsfund.org.uk/audio-video/ john-appleby-pressures-accident-and-emergency-services. Published 2014. Accessed Dec 20, 2016.

28. Jerant A, Bertakis KD, Fenton JJ, Franks P. Extended office hours and health care expenditures: a national study. Ann Fam Med. 2012;10(5):388-395.

29. Whittaker W, Anselmi L, Kristensen SR, et al. Associations between extending access to primary care and emergency department visits: a difference-in-differences analysis. PLoS Med. 2016;13(9):e1002113.

30. Kiran T, Victor JC, Kopp A, Shah BR, Glazier RH. The relationship between financial incentives and quality of diabetes care in Ontario, Canada. Diabetes Care. 2012;35(5):1038-1046.

31. Kiran T, Victor JC, Kopp A, Shah BR, Glazier RH. The relationship between primary care models and processes of diabetes care in Ontario. Can J Diabetes. 2014;38(3):172-178.

32. Li J, Hurley J, DeCicca P, Buckley G. Physician response to pay-forperformance: evidence from a natural experiment. Health Econ. 2014;23(8):962-978.

33. Kiran T, Kopp A, Glazier RH. Those left behind from voluntary medical home reforms in Ontario, Canada. Ann Fam Med. 2016;14(6):517-525

34. Dominiczak P, Cameron D. Tories will create a 'truly seven-day' NHS. The Telegraph. March 27, 2015.

35. Miller A. Liberals pledge guarantee of access to 24-7 primary health care by 2018. CP24. http://www.cp24.com/news/2014ontario-provincial-election/liberals-pledge-guarantee-of-access-to24-7-primary-health-care-by-2018-1.1845876. Published May 30, 2014. Accessed Nov 24, 2016.

36. Baker R, Walker N. Extended opening hours in primary care: helpful for patients and-or-a distraction for health professionals? BMJ Qual Saf. 2017;26(5):347-349. 